\title{
Reconstrucción de miembros inferiores por quemadura eléctrica evolucionada con colgajo sural bilateral
}

\section{Lower limb reconstruction after electrical burn evolved with bilateral sural flap}

Sergio Martínez ${ }^{1}$, Natalia Cotto Perroni², Silvana Rocío Nacir³, Brenda Aquino³, Facundo Haedo Pitteri³

\section{RESUMEN}

Describimos un enfoque simple y rápido para elevar colgajos fasciocutáneos surales y mostramos sus aplicaciones clínicas. El colgajo se elevó con fascia y manguito de tejido celular subcutáneo sobre piel. El pedículo distal se diseccionó hasta $5 \mathrm{~cm}$ sobre maléolo lateral, El sitio donante se injertó.

Los defectos fueron resultado de lesiones por quemaduras eléctricas del tercio distal de la pierna más exposición osteotendinosa.

Palabras claves: quemadura eléctrica, colgajo sural, exposición osteotendinosa.

\section{ABSTRACT}

We describe an easy and fast process to raise sural fasciocutaneous flaps and show its applications.The flap was raised with fascia and a sleeve of subcutaneous cellular tissue. The distal pedicle was dissected up to $5 \mathrm{~cm}$ over the lateral malleolus. Then the donor site was grafted. The defects were results of electrical burns of the distal third of the leg plus osteotendinous exposure.

Key words: electrical burn, sural flap, osteotendinous exposure.

REVISTA ARGENTINA DE CIRUGÍA PLÁSTICA 2019;25(2):89-92. HTTPS://DOI.ORG/10.32825/RACP/201902/0089-0092

\section{INTRODUCCIÓN}

La lesión por quemadura eléctrica ha llevado a hablar de "destrucción oculta". Hoy se acepta que el organismo actúa como un todo en la conducción de la energía eléctrica. La resistencia de los tejidos como el hueso genera calor y en la parte más distal de las extremidades se produce vasoconstricción, trombosis y necrosis isquémica progresiva que lesiona los músculos circundantes. Si se agrega desecación por exposición e infección, la necrosis progresiva es inevitable y con enormes consecuencias.

La reparación de estas lesiones de partes blandas del tercio distal de la pierna ha constituido un desafío para la cirugía plástica reconstructiva, ya que en la parte anterior de la pierna la tibia es muy vulnerable, porque está desprovista de protección muscular y está cubierta sólo por la piel, que es poco elástica y tiene una cantidad escasa de tejido subcutáneo, a todo lo largo de la

1. Jefe del Servicio de Cirugía Plástica y Quemados del Hospital J.C. Perrando. Resistencia, Chaco. Miembro titular SACPERNEA

2. Médica de planta del Servicio de Cirugía Plástica y Quemados del Hospital J.C. Perrando. Resistencia, Chaco. Miembro titular SACPERNEA

3. Residente del Servicio de Cirugía Plástica y Quemados del Hospital J.C. Perrando. Resistencia, Chaco.

$\square$ Correspondencia: Dra. Silvana Rocío Nacir. rocionacir@hotmail.com pierna, especialmente en la parte distal. Se evidencian

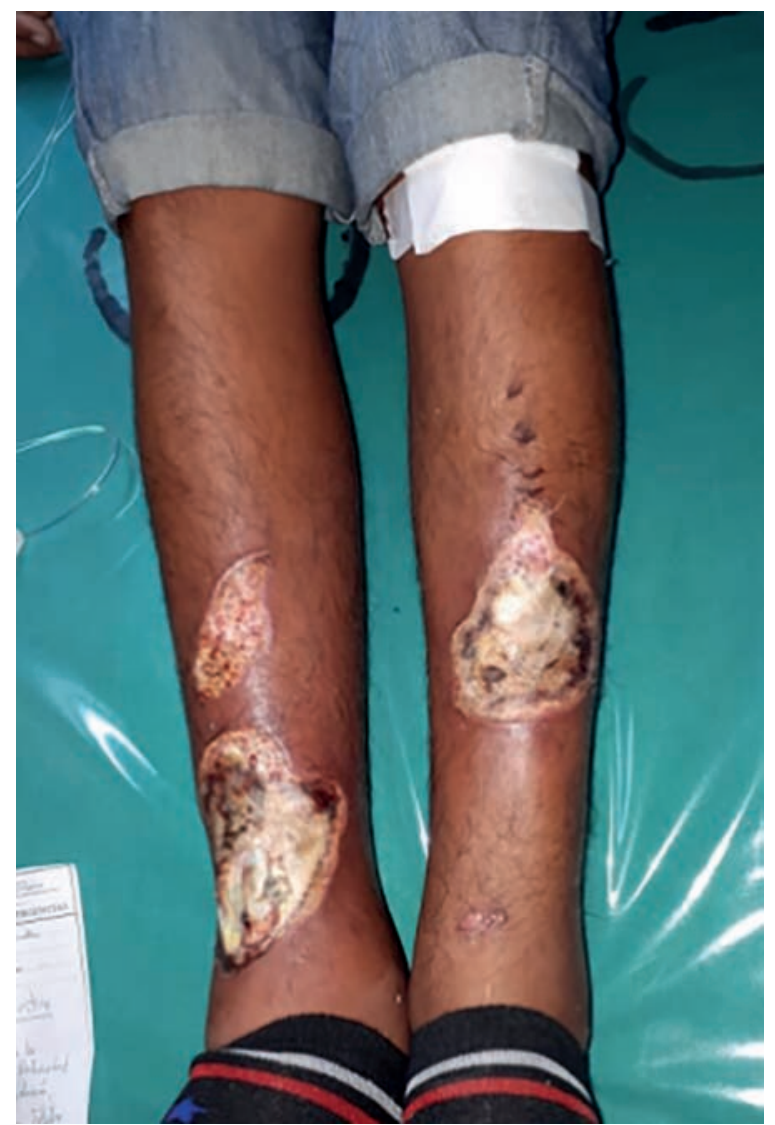

Figura 1. 


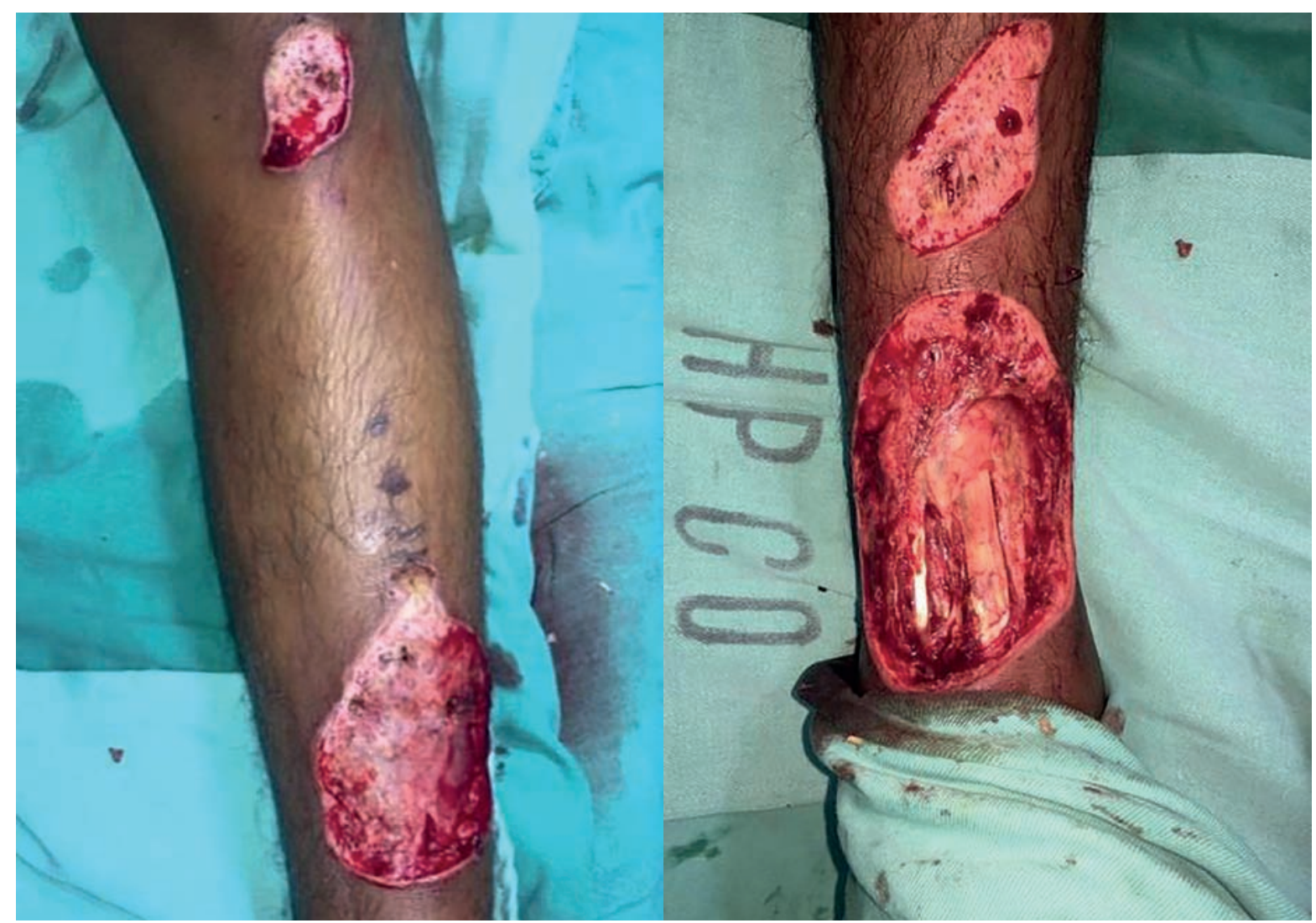

Figura 2.

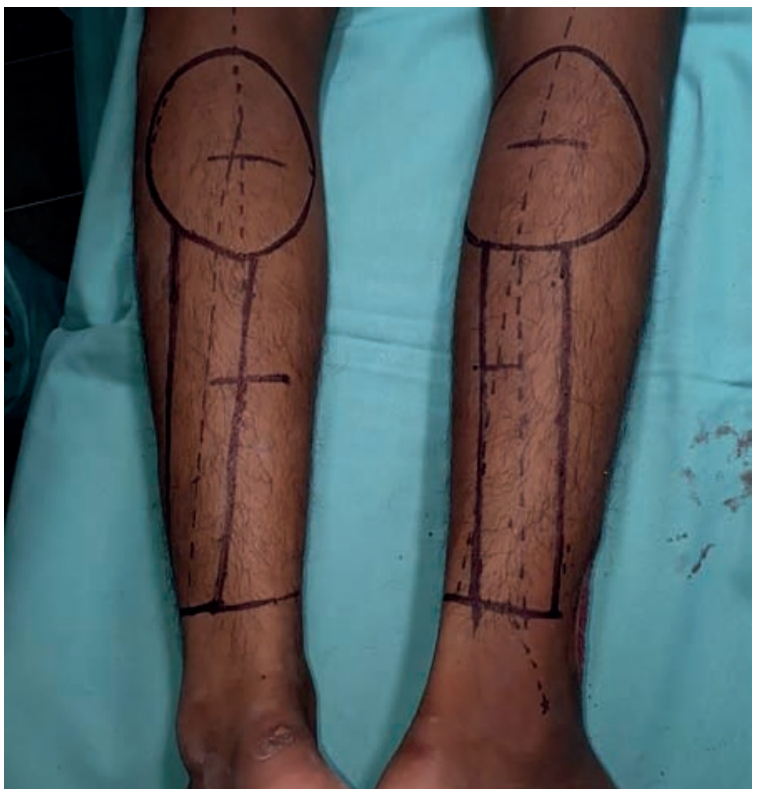

Figura 3.

numerosos procedimientos para la cobertura cutánea de estas regiones, siendo una excelente alternativa para estos defectos el colgajo sural ${ }^{1}$.

En 1889, Manchot describió por primera vez los territorios vasculares cutáneos; en 1892, Quenu y Lejars describieron las redes vasculares satélites que acompañan a los nervios cutáneos, mientras que en 1936, Salmón confirmó los estudios anteriores, basándose en sus propios estudios radiológicos, inyectando sustancias de contraste en los vasos sanguíneos.

En 1981, Franchinelli y sus colaboradores estudiaron la anatomía de la arteria sural superficial (inyectando en los vasos una sustancia de contraste) con el objetivo de diseñar un injerto vascularizado del nervio sural, y en 1983, Donski y Fogdestam describieron un colgajo fasciocutáneo con pedículo distal, basado en las arterias perforantes de la arteria peroneal.

$\mathrm{Al}$ año siguiente, Thatte y Laud presentaron un colgajo fascial con pedículo distal, localizado en la parte posterior de la pierna. En 1987, Ferreira y sus colaboradores presentaron un colgajo fasciocutáneo (medial o lateral) con pedículo distal, basado en perforantes septocutáneas, inframaleolares. Masquelet y sus colaboradores, en 1992, describieron el colgajo neurocutáneo en isla del nervio sural y lo usaron para reconstruir defectos de tejido blando en el tercio distal de la pierna y el tobillo ${ }^{2,3}$.

\section{MATERIALES Y MÉTODOS}

Se presenta el caso clínico de un paciente de 17 años con quemadura eléctrica evolucionada de 7 días con exposición osteotendinosa de $12 \times 7 \mathrm{~cm}$ aproximadamente en tercio distal de cara anterior de ambas piernas, la cual presentaba bordes necróticos (Figura 1).

Se realizaronsucesivas toilettes cada 48 horas hasta obtener zona granulante (Figura 2). 


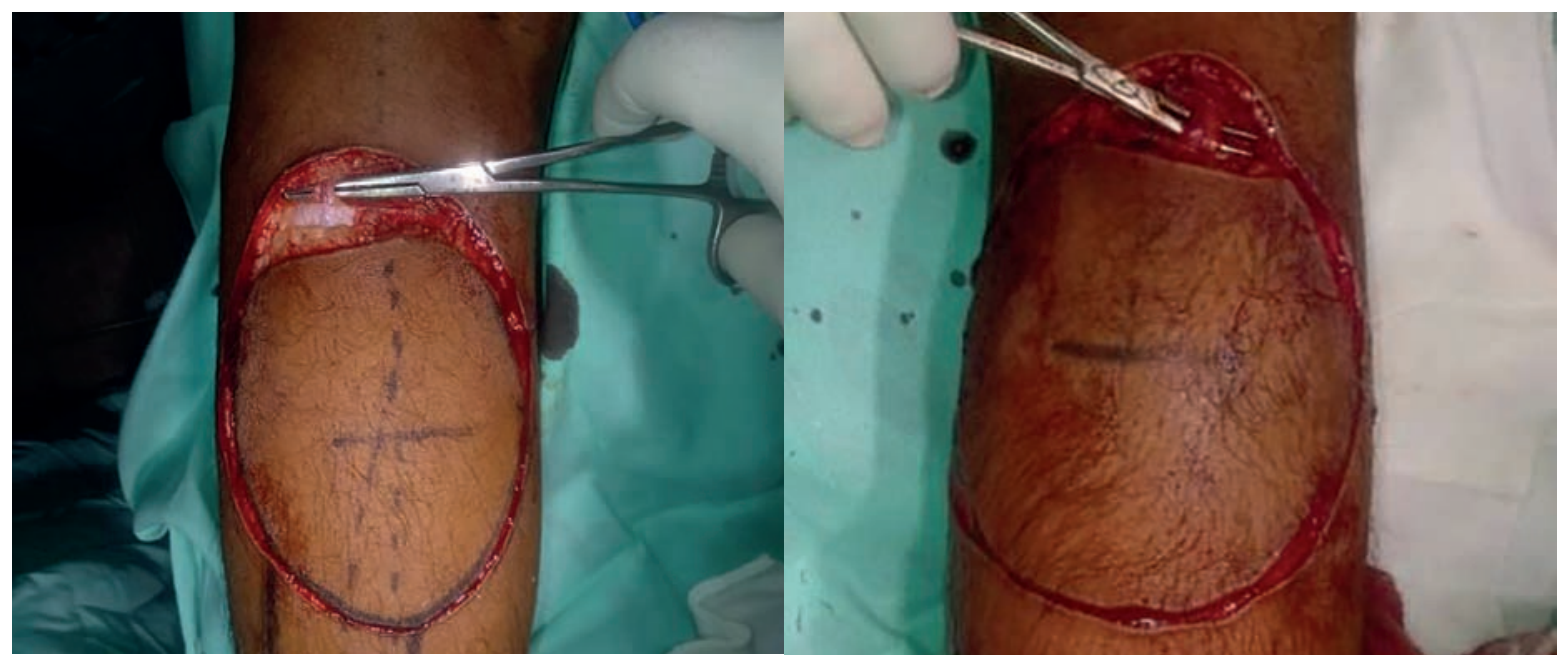

Figura 4.

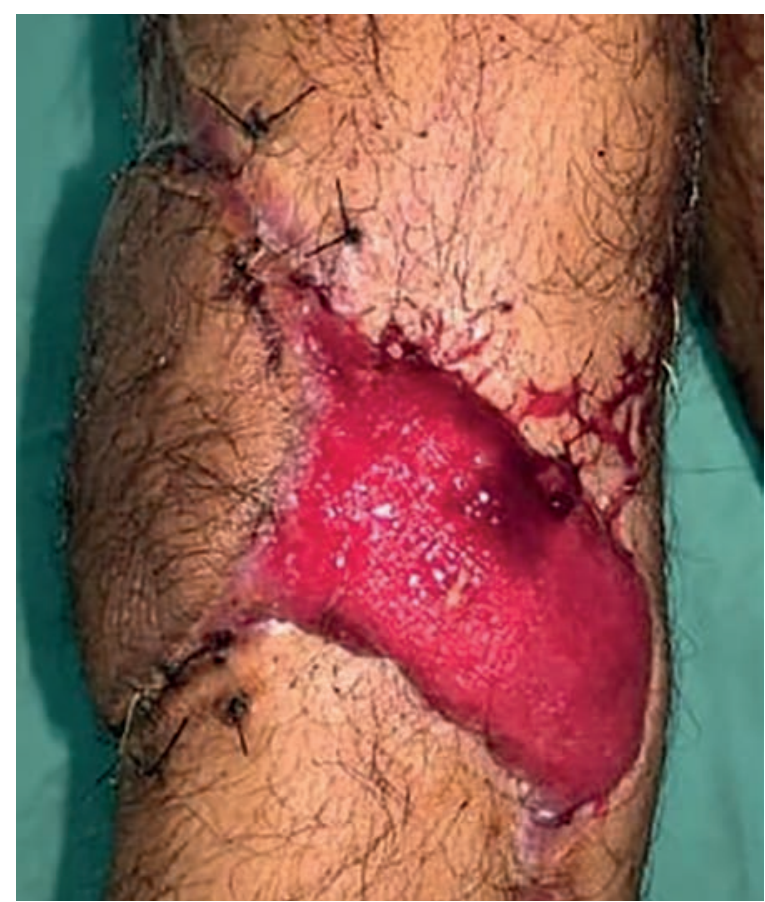

Figura 5.

Se diseña marcación de colgajo sural bilateral ( $\mathbf{F i}$ gura 3), en la cara posterior de la pierna, se marca el curso de la vena safena menor junto con una línea que va de la fosa poplítea hasta el maléolo lateral. En el tercio medio de la pierna, la vena safena indica la localización aproximada del septum (tabique) intermuscular posterior, por donde pasan las arterias perforantes fasciocutáneas con sus venas, las mismas que se originan en la arteria peroneal; generalmente las perforantes más grandes se encuentran a unos $5 \mathrm{~cm}$ por encima del maléolo lateral. El colgajo se orienta sobre la vena safena menor.

La incisión se realiza en la parte media de la pantorrilla en el borde superior del colgajo y se profundiza a través del tejido subcutáneo para identificar la vena safe-

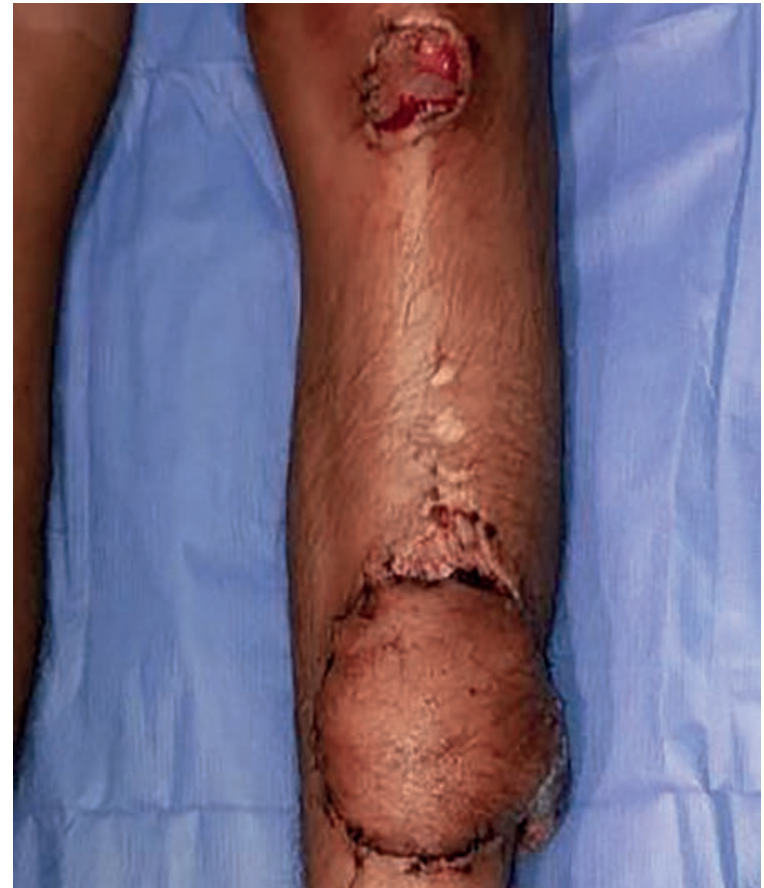

Figura 6.

na media y el nervio sural medio (Figura 4), que se encuentran encima de la fascia ${ }^{4}$.

El nervio sural medio, la arteria sural superficial medial y la vena safena menor, se ligan y se dividen, para incluir estas estructuras en el colgajo. Luego se dividió la fascia en la parte superior del colgajo y la disección continúa inferiormente en el plano subfascial, coagulando las perforantes musculocutáneas que emergen del músculo gastrocnemio, a medida que van apareciendo; la disección prosiguió hacia el perímetro del colgajo para elevarlo completamente 5,6

El pedículo (Figura 5) midió de 2 a $3 \mathrm{~cm}$ y, para asegurar su vascularidad, se incluyó una banda longitudinal de fascia que contiene el nervio sural, la vena safena menor y el plexo fascial que irriga el nervio. La disección del 


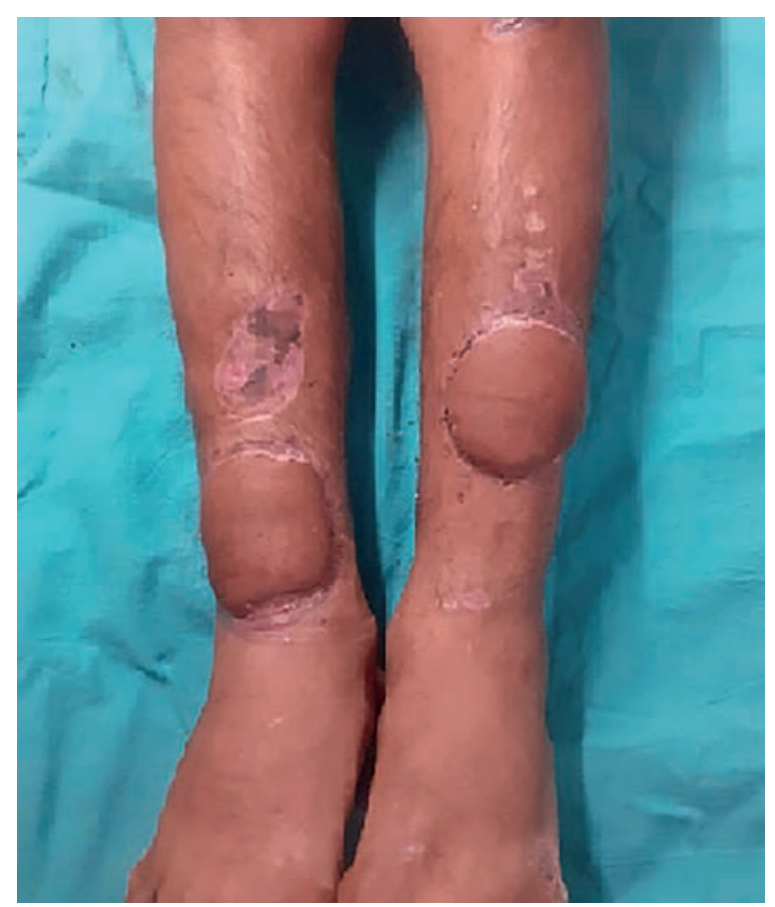

Figura 7. Adecuada evolución posoperatoria.

pedículo continuó hasta llegar a su punto de rotación y terminó a $5 \mathrm{~cm}$ más arriba del maléolo lateral ${ }^{7,8}$.

El defecto que quedó en la zona donante del colgajo después de levantarlo se cubrió con injerto de piel a espesor parcial.

El paciente ingresa a quirófano a las 72 horas, se evidencian colgajos vitales (Figura 6).

\section{RESULTADOS}

Ambos colgajos tuvieron evolución posoperatoria adecuada con buen suministro de sangre, contorno y función.

El colgajo fasciocutáneo sural es una alternativa simple y consistente para la reconstrucción distal de la extre-

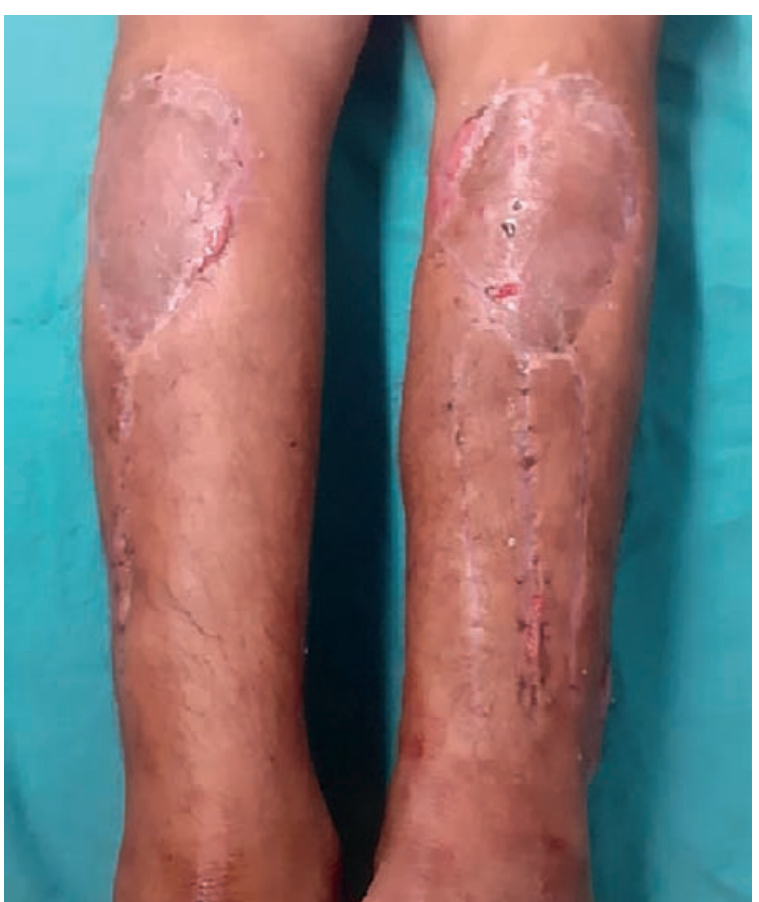

Figura 8. Posoperatorio alejado. Los colgajos muestran buen suministro de sangre, contorno y función.

midad inferior, principalmente cuando no hay microcirugía disponible.

\section{CONCLUSIÓN}

En este trabajo se demostró la efectividad del colgajo sural y proponerlo como pilar de la reconstrucción de la región distal de la pierna por quemadura eléctrica con exposición osteotendionosa, por la versatilidad de este, lo que permite una adecuada cobertura de la zona expuesta.

Priorizamos la escuela conservadora la cual se basa en debridamiento progresivos hasta que sea evidente que no existe más tejido desvitalizado.

\section{BIBLIOGRAFÍA}

1. Coiffman Cirugía Plástica, Reconstructiva ystética. Tercera Edición, Tomo I, capítulo

2. Coiffman Cirugía Plástica, Reconstructiva y Estética. Tercera Edición, Tomo IV, capítulo 380

3. Rouviere H. Anatomía humana, descriptiva y topográfi ca. Tomo III. Ed. Bailly-Bailliere, Madrid. 1980. Pp: 212-230.

4. Vasconez $L$, et al. Coverage of exposed bone by muscle transposition and skin grafting. Plastic Reconstr Surg 1994,96:526.
5. Mathes SJ, Nahai F. Principles generals. En: Mathes y Nahai. Reconstructive surgery. Principles, Anatomy \& Techniques. Ed. Churchill-Livingstone, 1997. Vol. I.

6. Mathes SJ, Nahai F. Clinical applications for muscle and musculocutaneous flaps. St. Louis, The C. V. Mosby Co., 1982.

7. Mc Carthy. Cirugía Plástica. Vol. 6. Cap. 7. Saunders Company; 1990.

8. Plastic and Reconstructive Surgey, Volume 102 number 1, january 2001. 